\title{
Effects of different material failures and surface contact on structural response of trailing edge sections in composite wind turbine blades
}

\author{
Chen, Xiao; Haselbach, Philipp Ulrich; Branner, Kim; Madsen, Steen Hjelm
}

Published in:

Composite Structures

Link to article, DOI:

10.1016/j.compstruct.2019.111306

Publication date:

2019

Document Version

Peer reviewed version

Link back to DTU Orbit

Citation (APA):

Chen, X., Haselbach, P. U., Branner, K., \& Madsen, S. H. (2019). Effects of different material failures and surface contact on structural response of trailing edge sections in composite wind turbine blades. Composite Structures, 226, [111306]. https://doi.org/10.1016/j.compstruct.2019.111306

\section{General rights}

Copyright and moral rights for the publications made accessible in the public portal are retained by the authors and/or other copyright owners and it is a condition of accessing publications that users recognise and abide by the legal requirements associated with these rights.

- Users may download and print one copy of any publication from the public portal for the purpose of private study or research.

- You may not further distribute the material or use it for any profit-making activity or commercial gain

- You may freely distribute the URL identifying the publication in the public portal 


\section{Journal Pre-Proof}

Effects of Different Material Failures and Surface Contact on Structural Response of Trailing Edge Sections in Composite Wind Turbine Blades

Xiao Chen, Philipp Ulrich Haselbach, Kim Branner, Steen Hjelm Madsen

PII:

S0263-8223(19)30555-0

DOI: https://doi.org/10.1016/j.compstruct.2019.111306

Reference:

COST 111306

To appear in:

\section{Composite Structures}

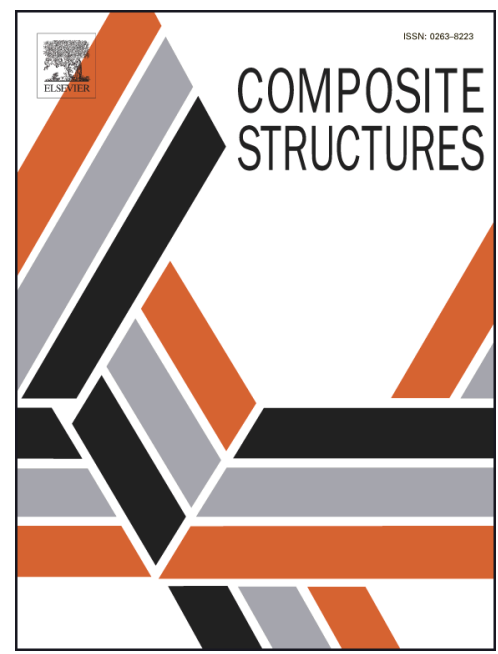

Received Date: $\quad 13$ February 2019

Revised Date: $\quad 6$ June 2019

Accepted Date: $\quad 31$ July 2019

Please cite this article as: Chen, X., Ulrich Haselbach, P., Branner, K., Hjelm Madsen, S., Effects of Different Material Failures and Surface Contact on Structural Response of Trailing Edge Sections in Composite Wind Turbine Blades, Composite Structures (2019), doi: https://doi.org/10.1016/j.compstruct.2019.111306

This is a PDF file of an article that has undergone enhancements after acceptance, such as the addition of a cover page and metadata, and formatting for readability, but it is not yet the definitive version of record. This version will undergo additional copyediting, typesetting and review before it is published in its final form, but we are providing this version to give early visibility of the article. Please note that, during the production process, errors may be discovered which could affect the content, and all legal disclaimers that apply to the journal pertain.

(C) 2019 Published by Elsevier Ltd. 


\title{
Effects of Different Material Failures and Surface Contact on Structural Response of Trailing Edge Sections in Composite Wind Turbine Blades
}

\author{
Xiao Chen*, Philipp Ulrich Haselbach, Kim Branner, Steen Hjelm Madsen \\ Technical University of Denmark, Department of Wind Energy \\ Frederiksborgvej 399, 4000 Roskilde, Denmark \\ *corresponding author: xiac@dtu.dk
}

\begin{abstract}
This paper presents a detailed numerical study on the structural response of a trailing edge segment from a composite wind turbine blade. The focus is placed on the effects of different material failures and surface contact, some of which are often not investigated in the conventional blade design, on the load-carrying capacity and the failure response of the trailing edge section subject to compressive loading. An advanced nonlinear Finite Element (FE) model capable of predicting different material failures and contact nonlinearities is used to facilitate parametric studies. Furthermore, we propose a possible method to improve the load-carrying capacity of the trailing edge section by structural reinforcement. The strengthening mechanism increases the buckling resistance of the trailing edge section almost to the level where the structure would fail due to the failure of composite materials, thereby utilizing the full strength of composites in the structure.
\end{abstract}

Keywords: Contact nonlinearity; reinforcement; failure mode; subcomponent test; sandwich panel; foam failure

\section{Introduction}

Trailing edge regions of large composite wind turbine blades are usually prone to buckling if there are wide unsupported panels when subjected to compressive and/or shear loads. Buckling is a geometrically nonlinear effect that may lead to other structural nonlinearities such as material failures and the change of contact and load conditions. In a previous study [1], we have tested a wind turbine blade trailing edge segment under compression and simulated its entire failure process using a nonlinear finite element (FE) analysis. It was found that the structural failure was primarily buckling driven with significant contributions from different material failures and the contact status of sandwich panels.

In conventional blade structural design, the geometric nonlinearity is often included while some material failures and contact conditions are often not considered in numerical models partly due to considerable modeling efforts, computational expenses or the availability of material damage models. Shell elements have been widely used in previous studies [2-4] together with the surface offset to model composite blades and their subcomponents. The shell element modeling approach is a very efficient way of modeling fiber composite structures. However, it only allows to predict in-plane stresses and strains and to apply in-plane failure criteria. In the shell element model, the accurate 
failure prediction of sandwich core materials, e.g., PVC foams, is impossible because critical out-ofplane shear loading and compressive loading in the core materials are neglected. The failure prediction of the core materials may be not accurate when layered solid element models are used with both composites and cores stacked in one single element through the thickness direction as presented in [5-7].

This study, which is a continuation of the previous work [1], examines the effects of different material failures and surface contact on structural response of trailing edge sections, taking advantage of the developed nonlinear FE model meshed with three-dimensional solid elements to explicitly represent composite materials and core materials in sandwich panels. The purpose of this work is to provide more insights into the important factors that influence the buckling behavior and the ultimate loadcarrying capacity of the trailing edge section when subjected to compressive loading. This is done by including different FE features and functions in the models. Based on this work, it is found that failure of foam core materials and surface contact can significantly affect the load-carrying capacity of the trailing edge section. Subsequently, structural reinforcement is proposed by introducing different reinforcement materials into the trailing edge regions where potential surface contact occur. Results show considerable increase of the load-carrying capacity of the specimen. In addition, this study presents the underlying strengthening mechanism and potential applications of the artificial reinforcements in the real blades.

\section{Description of subcomponent test and FE model}

In order to provide the relevant context of the current study, the previous work [1] is described here briefly. A trailing edge segment from a composite wind turbine blade has been tested quasi-statically to failure. The study examined its structural response under the loading condition when the trailing edge is under compression. A three-dimensional nonlinear FE model consisting of solid elements and cohesive elements was developed and incorporated with progressive failure analysis techniques as used in [8]. Multiple structural nonlinearities were considered in the model including the failures of composite materials, PVC foam cores and adhesive joints and the change of contact status between two sandwich panels during the loading. It was demonstrated that the FE model is able to predict the entire failure process including the post-peak response. The final failure characteristics of the specimen are shown in Fig. 1.

Fig. 1 The final failure of the trailing edge specimen (a) Deformation contour predicted by FEA (b) The specimen at the final failure (c) The failed trailing edge region

It has been found that the failure phenomenon was buckling driven. The surface contact between the two sandwich panels, i.e., the pressure and the suction side of the blades, and different material failures occurred sequentially along the load path, leading to a chain of events that determines the final failure of the specimen, see Fig. 2. 
Fig. 2 The predicted structural response of the trailing edge section [1]

Taking advantage of this nonlinear FE model, designated as Ori000 in the current study, the effects of different material failures and the surface contact on the structural response are examined. This is done by excluding the numerical functionality used to predict the corresponding structural nonlinearity in the FE model. The regions with different structural nonlinearities are shown in Fig. 3. In addition, considering different panel tapering in the trailing edge region gives different distances, or gaps, between two internal surfaces of sandwich panels, which may further change the contact status of two sandwich panels during the loading history. The effect of panel tapering is also examined by creating two additional FE models with slight changes in the tapering geometry. This is done by increasing the minimum distance between pressure and suction side panels in the tapering region two and three times, respectively. The two new FE models are designated as Ori100 and Ori200. The geometric modification is shown in Fig. 4.

Fig. 3 Structural nonlinearities considered in the FE models

Fig. 4 Different panel tapering in the trailing edge region

As such, a matrix of the parametric study is shown in Table 1. All simulation parameters are the same as those used in the previous study [1].

Table 1. FE models of the trailing edge specimen

\begin{tabular}{lcccc}
\hline \multirow{2}{*}{$\begin{array}{l}\text { FE model } \\
\text { designation }\end{array}$} & \multicolumn{3}{c}{ Different structural nonlinearities included in the FE model } \\
\cline { 2 - 5 } & Surface contact & Composite failure & Foam core failure & Adhesive failure \\
\hline Ori000 & Yes & Yes & Yes & Yes \\
NoComf & Yes & No & Yes & Yes \\
NoFoaf & Yes & Yes & No & Yes \\
NoAdhf & Yes & Yes & Yes & No \\
NoMatf & Yes & No & No & No \\
NoCont & No & Yes & Yes & Yes \\
GeoNon & No & No & No & No \\
Ori100 & Yes & Yes & Yes & Yes \\
Ori200 & Yes & Yes & Yes & Yes \\
\hline
\end{tabular}

\section{Results and discussion}

The global structural response of the trailing edge section of different models is shown in Fig. 5 . The applied load $P$ is normalized by the maximum applied load during the test, $P_{\text {peak }}=99.2 \mathrm{kN}$ and the displacement $\delta$ is normalized by the total length of the specimen $I_{0}=3 \mathrm{~m}$.

\subsection{The effects of material failures}

As shown in Fig. 5(a), the exclusion of the PVC foam failure in the FE model results in a significant difference in the post-peak response. The trailing edge specimen could deform considerably more without much decrease of the load-carrying capacity. Nevertheless, the peak load of the FE model 
without PVC foam failure is only slightly higher than the FE model including PVC foam failure. When the failure of composites and adhesives is not included in the FE model, the change of the structural response is significant in neither cases as shown in Fig. 5(b) and 5(c) compared to the FE model including all structural nonlinearities. Moreover, the peak load is not affected by the failure of composites or adhesives, which occurs only in the post-peak regime. If no material failures is included in the FE model, the specimen exhibits a plateau-like response after the initial linear regime as shown in Fig. 5(d). This FE model overestimates the peak load slightly due to the exclusion of the foam failure.

Fig. 5 Global structural response of the trailing edge section using different FE models. Comparing to the original FE model (a) the FE model without foam failure shows quite different post-peak response; (b) the FE model without composite failure shows no significant difference; (c) the FE model without adhesive failure shows no significant difference; (d) the FE model without any material failure shows quite different post-peak response; (e) the FE model without surface contact shows quite different structural response even before the peak load is reached; (d) the FE model only including geometric nonlinearity shows quite different structural response

These results have an interesting implication to the current blade design: the failure of foam materials could affect the structural response more than the failure of composite materials and adhesive materials. This finding is rather new to the existing knowledge base. Foam materials are usually modeled as elastic materials assuming they do not fail and the other two presumably more loadcarrying materials, i.e., the composite materials and adhesive materials are verified against failure as a routine procedure in the blade design. This is because most blade FE models in blade design use shell elements to represent sandwich panels with both skin laminates and core materials stacked in one single shell element. This modeling approach makes it impossible to predict the foam failure that requires an explicit element representation of the foam materials between two skin laminates. Furthermore, the foam materials, in general, have a much larger strain at failure than composite materials, which might lead to an inaccurate perception that they would not fail before the adjacent composites. This study demonstrates that foam failure could occur before the composite failure and affect the structural response significantly. More attention should be paid to the potential foam failure in the blade design.

\subsection{The effects of surface contact}

Fig. 5(e) shows significant differences in the structural response if surface contact constraints between the pressure and suction side sandwich panels are not included in the FE model. Not only the peak load is considerably underestimated but also the structural response beyond the linear regime differ significantly from the original FE model Ori000. This is because the FE model NoCont without the surface contact shows panels penetrations when loaded as shown in Fig. 6. This is of course not realistic in the actual experiment. In addition, the foam failure is predicted to occur in one 
region close to the trailing edge due to the removal of the surface contact, while the experimental observations [1] showed the foam failure in two regions as predicted by the original FE model Ori000.

Fig. 6 Deformation and foam failure of Ori000 and NoCont at the peak load

(PEEQ: Equivalent plastic strain)

When both surface contact and material failures are excluded and only geometric nonlinearity is considered in the FE model, i.e., GeoNon as shown in Fig. 5(f), the structural response is similar to the results from the FE model NoCont but with more deformation at the peak load. The applied load versus the deformation curve differs significantly from the original FE model. It should be noted that the peak load happens to be close to the original FE model. This is due to the combinations of the overestimation of the FE model NoMatf and the underestimation of the FE model NoCont. Neither model predicts the structural response of the trailing edge section correctly as discussed previously.

\subsection{The effects of panel tapering}

Based on the aforementioned discussion, it is known that the surface contact significantly affects the overall structural response of the trailing edge section. The effect of the minimum distance, or the gap, between two internal surfaces of sandwich panels is of interest to investigate. The minimum distance can be quite arbitrary, or difficult to control, as it depends largely on how the foam materials are machined and how they are infused during the blade manufacturing process. The purpose of tapering the foam near the trailing edge region is to avoid material interference when the blade mold closes. This is especially important for the blades with thin airfoil cross section profiles in the trailing edge.

Fig. 7 Effects of different minimum distances in the tapering region

As shown in Fig. 7, a considerable decrease of the peak load is observed when the minimum distance between two internal surfaces in the tapering region increases. This is reasonable considering that the smaller gap results in earlier surface contact, which imposes additional constraints to the panels, increasing their buckling resistance and the loading-carrying capacity as a favorable consequence, and vice versa. It is noted that the buckling resistance is also affected due to different tapering distances which lead to different surface contact during the loading history. The surface contact areas of different designs at the peak load are shown in Fig. 8. The overall structural stiffness, or the slope of the linear response, does not change due to very slight differences of panel thickness in the tapering region in three FE models. 
Fig. 8 Surface contact regions shown in black in different designs at the peak load

(COPEN: The clearance between two contact surfaces. The pressure side panel is removed for better visualization)

\section{Proposed structural reinforcement}

\subsection{The FE models with structural reinforcement}

Following the findings from the previous sections, it is natural to think that it might be possible to improve the load-carrying capacity of the trailing edge section by imposing additional constraints to the two panel surfaces in the tapering region. To examine the feasibility of this idea, a new FE model is created based on the FE model Ori000 by adding materials, or artificial reinforcement, to connect the two panel surfaces that might contact during the loading. Three materials are considered for the reinforcement and they are PVC foam, which is the same as the one used in the trailing edge section, balsa wood and adhesive glue. Their material properties are shown in Table 2.1-2.3.

Table 2.1. Material properties of the PVC foam [1]

\begin{tabular}{ccccc}
\hline $\begin{array}{c}\rho \\
\mathrm{kg} / \mathrm{m}^{3}\end{array}$ & $\begin{array}{c}E \\
\mathrm{MPa}\end{array}$ & - & $\begin{array}{c}\sigma_{\mathrm{y}} \\
\mathrm{MPa}\end{array}$ & $\begin{array}{c}\varepsilon_{\mathrm{y}} \\
\%\end{array}$ \\
\hline 60 & 48.5 & 0.4 & 1.4 & 2.89 \\
\hline$\sigma_{\mathrm{y}}, \varepsilon_{\mathrm{y}}$ are the yielding stress and strain of PVC foam, respectively.
\end{tabular}

Table 2.3. Material properties of the balsa wood (assumed based on [9])

\begin{tabular}{cccccccccc}
\hline $\begin{array}{c}\rho \\
\mathrm{kg} / \mathrm{m}^{3}\end{array}$ & $\begin{array}{c}E_{11} \\
\mathrm{MPa}\end{array}$ & $\begin{array}{c}E_{22} \\
\mathrm{MPa}\end{array}$ & $\begin{array}{c}E_{33} \\
\mathrm{MPa}\end{array}$ & $\begin{array}{c}v_{12} \\
-\end{array}$ & $\begin{array}{c}v_{13} \\
-\end{array}$ & $\begin{array}{c}v_{23} \\
-\end{array}$ & $\begin{array}{c}G_{12} \\
\mathrm{MPa}\end{array}$ & $\begin{array}{c}G_{13} \\
\mathrm{MPa}\end{array}$ & $\begin{array}{c}G_{23} \\
\mathrm{MPa}\end{array}$ \\
\hline 90 & 700 & 700 & 1385 & 0.3 & 0.3 & 0.3 & 40 & 78 & 78 \\
\hline
\end{tabular}

Table 2.3. Material properties of the adhesive material [1]

\begin{tabular}{cccccccccc}
\hline$\rho$ & $E$ & $v$ & $\sigma_{33^{\mathrm{u}}}$ & $\sigma_{13}{ }^{\mathrm{u}}$ & $\sigma_{23}{ }^{\mathrm{u}}$ & $G_{\text {Ic }}$ & $G_{\text {IIc }}$ & $G_{\text {IIIc }}$ & $\eta$ \\
$\mathrm{kg} / \mathrm{m}^{3}$ & $\mathrm{MPa}$ & - & $\mathrm{MPa}$ & $\mathrm{MPa}$ & $\mathrm{MPa}$ & $\mathrm{N} / \mathrm{m}$ & $\mathrm{N} / \mathrm{m}$ & $\mathrm{N} / \mathrm{m}$ & - \\
\hline 1180 & 3000 & 0.38 & 42 & 40 & 40 & 1200 & 6000 & 6000 & 1.75 \\
\hline
\end{tabular}

$G_{\mathrm{Ic}}, G_{\mathrm{II}}, G_{\mathrm{IIIc}}$ are the critical energy release rates for Mode I, II and III fracture, respectively. $\eta$ is a material constant defined in the Benzeggagh-Kenane fracture criterion [10].

The three FE models with different reinforcement materials have the same geometry as shown in Fig. 9. They are analyzed taking into account all structural nonlinearities as in the FE model Ori000. Fig. 10 shows that the peak load or the maximum load-carrying capacity of the trailing edge section with the proposed reinforcement methods is increased significantly. Moreover, the global structural response is almost linear with a slight nonlinear regime before the peak load. The post-peak response is a sudden drop of the load-carrying capacity rather than the gradual drop as observed in the original design.

Fig. 9 FE models with different reinforcement materials in the trailing edge panel-tapering region 
Fig. 10 Structural response of the trailing edge section after reinforcement

\subsection{Strengthening mechanism}

In order to understand the strengthening mechanism of the proposed reinforcement, the failure processes of the trailing edge section along the load path are examined, see Fig. 11. In this figure, only the results from the FE model reinforced with the PVC foam are shown to represent the similar overall trends found in other two reinforcement cases. Due to the reinforcement materials in the tapering region, the two sandwich panels do not contact during the loading as they do in the original design. The reinforcement stabilizes the sandwich panels in the trailing edge region and increase the buckling resistance of the entire specimen as shown in Fig. 12(a) and (b). The foam material used in the reinforced region fails at the peak load while the foam materials in the sandwich panels remain intact. Comparatively, the original design shows the prevailing foam failure in the sandwich panels when they contact and compress each other. The two other reinforcement materials, i.e., balsa wood and adhesive glue, do not fail before the peak load. Only minor foam failure occurs locally in the sandwich panels as shown in Fig. 12(c) and (d).

Fig. 11 Comparison of failure processes between the original and the reinforced specimen

Fig. 12 Comparison of the foam failures between different designs at the peak load (PEEQ:

Equivalent plastic strain in the foam) (a) The original design without reinforcement (b) Reinforced with PVC foam (c) Reinforced with balsa wood (d) Reinforced with adhesive

It is important to note that for all reinforced designs, the peak load is also the load level when the failure of composite materials starts as indicated in Fig. 11. The matrix-dominant failure occurs at the peak load, immediately followed by the delamination and the fiber-dominant failure. With the proposed reinforcement, the maximum load-carrying capacity of the trailing edge section increases considerably as the buckling response is postponed in the loading history almost until the structure would fail due to composite material failure, thereby utilizing the full strength of materials in the structure. In the original design, the maximum load-carrying capacity of the trailing edge section is primarily driven by the buckling phenomenon which occurs rather early in the load history.

\subsection{Potential applications}


In order to apply proposed structural reinforcement to the blades, a few possible methods may be used. Fig. 13 conceptually illustrates two possible methods for potential applications. For the new blades, prefabricated core materials are placed in the trailing edge regions to reduce the distance between two internal surfaces of sandwich panels; subsequently, adhesive material is applied to glue these internal surfaces. The thickness of the prefabricated core materials should be determined in such a way that the usage of adhesive is small and no interference occurs between two internal surfaces when closing the blade mold. For the existing blades, it is not possible to open two shells of the blades. In these cases, trailing edge sections could be reinforced by injecting liquid foams or adhesive that later solidate in the regions where surface contact may occur. A few holes need to be drilled in the sandwich panels in order to perform this reinforcement. It is noted that some practical issues such as manufacturability and field implementation are not discussed in this work and further study is needed before these methods can be applied in the real blades.

Fig. 13 Conceptual illustration of possible methods for reinforcing trailing edge sections (a) Gluing sandwich panels together in the new blades (b) Injecting liquid foams or adhesive in the existing blades

\section{Conclusions and future study}

A few conclusions can be drawn from this study:

- Foam core materials in sandwich panels could significantly affect the load-carrying capacity and the failure behavior of the trailing edge section under compression. This study highlights the necessity and importance of verifying the potential failure of foam core materials in the blade design.

- The contact constraint between two internal surfaces of sandwich panels increases the buckling resistance and the maximum load-carrying capacity of the trailing edge section under compression. The tapering of sandwich panels is important when the surface contact in the trailing edge region is likely to occur.

- A structural reinforcement is proposed by connecting two internal surfaces of two sandwich panels using either core materials or adhesives at the locations where they may contact when loaded. It is possible to apply the proposed reinforcement to the new blades by gluing two panels using adhesive when the mold closes and to the existing blades as a retrofit solution by injecting liquid foams or adhesive in trailing edge regions.

- The strengthening mechanism increases the buckling resistance of the trailing edge section almost to the level where the structure would fail due to composite material failure, thereby utilizing the full strength of composite materials in the structure. As a result, the maximum loadcarrying of the structure is increased.

This study focuses on a specific wind turbine blade trailing edge section under compression. Several issues remain to be investigated such as the effect of load combinations, the implementation of the 
proposed reinforcement in the real blades, the experimental validation and the effect of the increased stiffness and strength as well as the consequence on fatigue. They will be future work.

\section{Author Contributions}

Xiao Chen designed and performed the numerical study and wrote the manuscript. Kim Branner and Xiao Chen contributed to the reinforcement idea and discussed the idea of writing this paper. Kim Branner, Philipp Ulrich Haselbach and Steen Hjelm Madsen reviewed, revised and commented on the manuscript.

\section{Acknowledgments}

This study is partly funded by the Danish Energy Technology Development and Demonstration Program (EUDP) through the ReliaBlade project (No. 64018-0068). We would thank Jing Tang for meshing FE models, Sergei Semenov for comments on this manuscript and Peter Berring for technical discussion. We would like to thank anonymous reviewers for their valuable suggestion and comments on this work.

\section{References:}

[1] Chen X., Berring P, Madsen SH, Branner K, Semenov S, Understanding progressive failure mechanisms of a wind turbine blade trailing edge section through subcomponent tests and nonlinear FE analysis, Composite Structures. https://doi.org/10.1016/j.compstruct.2019.02.024

[2] Chen X., Qin ZW, Yang K, Zhao XL, Xu JZ, Numerical analysis and experimental investigation of wind turbine blades with innovative features: Structural response and characteristics, Science China Technological Sciences, Volume 58, Issue 1, January 2015, Pages 1-8.

[3] Haselbach PU, Eder MA, Belloni F., A comprehensive investigation of trailing edge damage in a wind turbine rotor blade, Wind Energy, 2016. 19:1871-1888.

[4] Lahuerta F., Koorn N, Smissaert D., Wind turbine blade trailing edge failure assessment with sub-component test on static and fatigue load conditions, Composite Structures, 204 (2018) 755766.

[5] Chen X., Zhao W., Zhao XL, Xu JZ, Failure test and finite element simulation of a large wind turbine composite blade under static loading. Energies. Volume 7, Issue 4, 2014, Pages 22742297.

[6] Rosemeier, M., Berring, P., Branner, K. (2016) Non-linear ultimate strength and stability limit state analysis of a wind turbine blade. Wind Energy, 19: 825 - 846. doi: 10.1002/we.1868.

[7] Chen X., Zhao XL, Xu JZ, Revisiting the structural collapse of a $52.3 \mathrm{~m}$ composite wind turbine blade in a full-scale bending test, Wind Energy, vol: 20, issue: 6, pages: 1111-1127, 2017.

[8] Chen X., Tang J., Yang K., Modeling multiple failures of composite box beams used in wind turbine blades, Composite Structures. https://doi.org/10.1016/j.compstruct.2019.03.018

[9] DIAB ProBalsa ${ }^{\circledR}$ LD7 Light Weight Balsa Wood, www.matweb.com, retrieved on June 6, 2019.

[10] Benzeggagh, ML, Kenane M, Measurement of Mixed-Mode Delamination Fracture Toughness of Unidirectional Glass/Epoxy Composites with Mixed-Mode Bending Apparatus, Composites Science and Technology, vol. 56, pp. 439-449, 1996. 
